\title{
Roadside mowing spreads yellow bristle grass (Setaria pumila) seeds further than by natural dispersal
}

\author{
Trevor K. James ${ }^{1 *}$, Michael R. Trolove ${ }^{1}$ and Claire A. Dowsett ${ }^{1,2}$ \\ ${ }^{1}$ AgResearch, Ruakura Research Centre, Private Bag 3123, Hamilton 3240, New Zealand \\ ${ }^{2}$ Department of Conservation, 34-36 Taupo Quay, Whanganui 4500, New Zealand \\ *Corresponding author: trevor.james@agresearch.co.nz
}

\begin{abstract}
Yellow bristle grass is a highly invasive annual $\mathrm{C}_{4}$ pasture weed that has spread rapidly through many New Zealand dairying regions via seed dispersal. Seven trials were conducted on roadsides infested with yellow bristle grass to evaluate natural and mowerassisted dispersal. To trap seeds, yellow sticky traps were laid out at various intervals both perpendicular to and parallel to the road. Traps were in place for $24 \mathrm{~h}$ in the four natural dispersal trials but only for the event in the mowing trials. Seeds on the retrieved traps were counted and the seeds caught in the mower estimated. For natural dispersal, $90 \%$ of seeds fell within $0.5 \mathrm{~m}$. When mown, $90 \%$ of the seeds fell within 2 metres in the direction of mowing and $80 \%$ within $20 \mathrm{~cm}$ in the perpendicular direction. More importantly, a small percentage of dispersed seeds were caught in the mower and presumably could subsequently fall off anywhere. Mowing mature yellow bristle grass on the roadside will result in accelerating seed dispersal along the roadside for many metres and potentially many kilometres.
\end{abstract}

Keywords yellow bristle grass, Setaria pumila, $\mathrm{C}_{4}$ grass weed, roadside mowing, seed dispersal, road corridors.

\section{INTRODUCTION}

Yellow bristle grass (Setaria pumila (Poir.) Roem. \& Schult.) is an invasive summer $\mathrm{C}_{4}$ annual grass which lowers production of infested pastures (James et al. 2009; Tozer et al. 2014). It had invaded many dairy farms throughout Waikato within 10 years of its first observation on farms around Te Pahu and Paterangi in eastern Waikato in 2004 (Tozer et al. 2012). Yellow bristle grass seed has no natural appendages (such as awns) to assist dispersal; the bristles from which it obtains its name are attached to the stem and not to the seed. Mature seeds fall free leaving the bristle attached to the main stem (Champion et al. 2012). Increasingly, anthropogenic activities are recognised as major drivers of dispersal of plants with roadways frequently identified as major pathways (Christen \& Matlack 2006; Birdsall et al. 2012). In addition, mowing provides a disturbance that can facilitate weed seed germination and establishment.

Transportation of feed and grain on roads has previously been identified as a contributing pathway for dispersal of yellow bristle grass seed in New Zealand (James et al. 2015) and of other species overseas (Bailleul et al. 2012). Vehicles (Clifford 1959) and livestock (Hogan \& Phillips 2011) have previously been identified as contributing pathways but the role of roadside mowing is only referenced in passing (Bryson \& Carter 2004; Kalwij et al. 2008).

The aim of this study was to determine if (and how far) yellow bristle grass seed might be dispersed by natural means or by roadside mowing.

\section{MATERIALS AND METHODS}

Seven roadside trials were carried out in Waikato, New Zealand. Trials 1-4 involved natural dispersal and Trials 5-7 involved mower 
dispersal. Trials 1 and 2 were set up on Anderson Road, Ngāhinapōuri, on 11 February 2013, and Trials 3 and 4 on Te Pahu Road, Whatawhata on 12 February 2013. Trials 5 and 6 were set up on Ringer Road, Pukemoremore, on 27 February 2014 and Trial 7 on Duncan Road, Tamahere, on 6 March 2014. Yellow bristle grass stems with seed heads ranging from immature to postshattering were present on all Trials except Trial 5 where no post-shattering seed heads were present. For each trial, a patch of yellow bristle grass at least $5 \mathrm{~m}$ long and with less than 5\% other species, was used. The yellow bristle grass was up to $30,40,50,60,30,50$ and $80 \mathrm{~cm}$ tall for Trials 1-7 respectively. The wind was Beaufort Force 1 (light air, 1-6 km/hr) on each trial day.

To establish a base line for seed dispersal, all vegetation was mown and removed from the exit end (for passing vehicles or the mower) of the yellow bristle grass patch but not the patch itself. Sticky yellow paper traps $(20 \times 22 \mathrm{~cm})$ were used to collect yellow bristle grass seeds that were dispersed over $24 \mathrm{~h}$ (Trials 1-4) or after mowing was completed (Trials 5-7). Traps were laid out both parallel to the line of travel and perpendicular to it as shown in Figures 1 and 2 (Trials 1 and 5 respectively) and pinned down with nails. The layout of traps for Trials 2-4 (natural dispersal) were similar to Trial 1 but Trials 6 and 7 (mower dispersal) differed from Trial 5 (mower dispersal) by laying perpendicular traps on both sides of the mown strip, to test if the mower was spreading seeds equally on both sides, and to a maximum distance of 4.5 $\mathrm{m}$ parallel to the mown strip. For Trials 5-7, the mower then made a single pass through the yellow bristle grass patch and continued over the sticky traps. For these trials, a tractor-mounted, dual-blade rotary-type mower was used as supplied by the roading contractor but the exact equipment varied. Traps were retrieved after $24 \mathrm{~h}$ to evaluate wind dispersal and immediately after mowing for mower dispersal of mature yellow bristle grass seeds then returned to the laboratory to count the seeds. The type of seed (free or still attached to the seed head) was also noted. Additionally, for the mowing trials, an approximate $1 \mathrm{~kg}$ sample of the cut grass mulch adhering to the underside of the mower was collected and the visible 'free' seeds sitting on top of the mower were counted. The cut-grass mulch was weighed then mixed 50:50 v:v with potting mix (Daltons, 15\% bark fibre, 50\% C.A.N. fines A grade, $15 \%$ coco fibre classic (Profit) and 20\% pumice $(7 \mathrm{~mm}))$ then laid out in the glasshouse with regular watering and temperatures between $15-25^{\circ} \mathrm{C}$. Emerging yellow bristle grass plants were counted after 4 weeks.

The empirical data from the seven trials are presented here but due to differences in the sample sizes, no statistical analysis was carried out. The count data was plotted with a squareroot scale to avoid the problem associated with zeros on a log scale. The distance seeds were moved was determined for both perpendicular (left and right) and parallel movement.

\section{RESULTS}

The numbers of yellow bristle grass seeds collected on each of the yellow sticky traps for all seven trials are presented in Figure 3. Natural dispersal of yellow bristle grass seeds was similar in both directions with $70 \%$ and $66 \%$ of seeds on the perpendicular and parallel traps that were $0-0.25 \mathrm{~m}$ from the patch respectively. Seeds on the perpendicular and parallel traps that were $0.25-0.5-\mathrm{m}$ from the patch represented $21 \%$ and $24 \%$ of the total count respectively, and $8 \%$ and $10 \%$ for the traps $0.5-0.75-\mathrm{m}$ away. In the perpendicular direction only, $2 \%$ of the seeds reached the traps placed $0.75-1 \mathrm{~m}$ from the patch.

Seed dispersal by mowing along the roadside was more variable with seed numbers ranging between tens to just under 1500 seeds on traps each 2-metres from the patch. Greater than $90 \%$ of the seeds was detected in the first $2 \mathrm{~m}$ away from the patch. For Trials 6 and 7, the furthest sticky trap was located $4.5 \mathrm{~m}$ from the seed source. In Trial 6 this trap contained three seeds but in Trial 7 there were no seeds collected beyond 2.5 $\mathrm{m}$. In the perpendicular direction, $80 \%$ of the collected seeds were found within $20 \mathrm{~cm}$ of the side of the mower but were detected as far away 


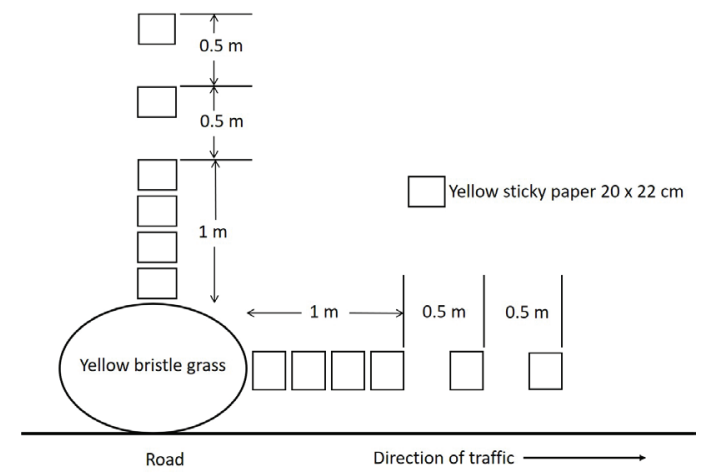

Figure 1 Layout of Trials 1-4 (natural dispersal) showing position of yellow sticky traps in relation to the yellow bristle grass patch and the roadside.

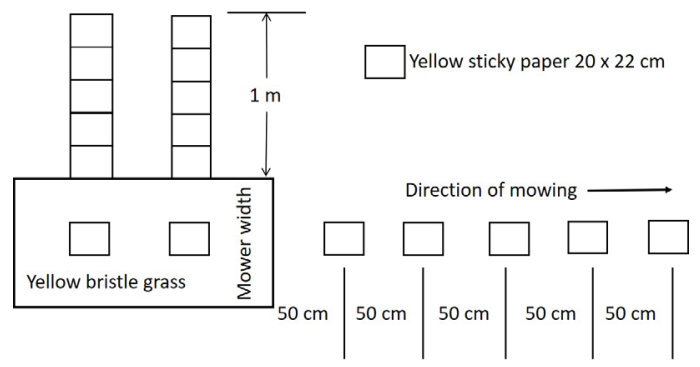

Figure 2 Layout of Trial 5 (dispersal by mowing) showing position of yellow sticky traps in relation to the yellow bristle grass and the mowing swath. Note that Trials 6 and 7 had sticky traps on both sides of the $2-\mathrm{m}$ wide mower.

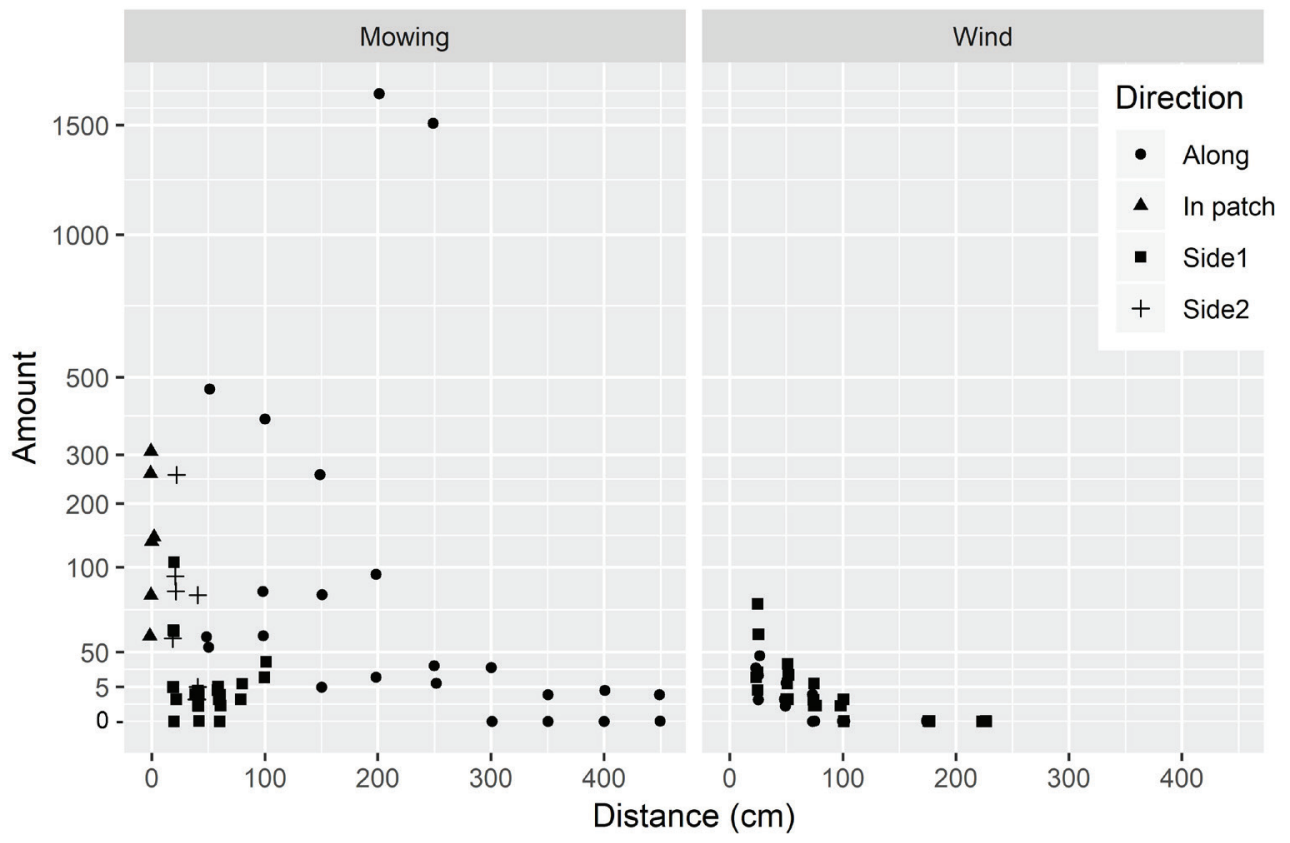

Figure 3 Number of yellow bristle grass seeds on each of the yellow sticky traps for all seven trials. The vertical axis is a square root scale and the points are offset to prevent overlap. Symbol key indicates the location of the traps, Side 1 is the left-hand side and Side 2 the right-hand or road-side of the layout.

as $1 \mathrm{~m}$, the maximum distance sampled. Number of seeds on the sticky traps set within the mown region of the trials (Fig. 2) were 67 and 137, 31 and 144, and 259 and 308 for Trials 5, 6 and 7 respectively. An observation was made when the seeds were counted that for Trial 5, >95\% of the seeds were still attached to the rachis of the seed head whereas in all the other trials $>95 \%$ of the seeds counted were single seeds free of the rachis.

The numbers of seeds that germinated in the samples of cut grass mulch from under the mower and the counts of 'free' seeds on top of the mower are presented in Table 1. 


\section{DISCUSSION}

These results show that mowing disperses yellow bristle grass seeds further than by natural means. However, $90 \%$ of the seed was collected within $2 \mathrm{~m}$ of the mowing location, which indicates the distances that seeds were moved by the mowing process remains small and unlikely to be a major factor in dispersal. If only a single mowing event coincides with seeding each year, it would take about 25 years for yellow bristle grass to move 1 kilometre along the road, in contrast to 50100 years by natural dispersal. Seeds lacking dispersal appendages are considered not to be widely dispersed by natural means (Hintze et al 2013) but Ernst et al. (1992) found that Setaria verticillata, with an infructescence of $0.8 \mathrm{~m}$, has a potential dispersal distance of $0.82,1.64$ and $3.28 \mathrm{~m}$ in winds of $2.5,5$ and $10 \mathrm{~m} / \mathrm{s}$ respectively. Setaria verticillata is very similar to yellow bristle grass and there is no reason that the dispersal of their seeds should differ. On the Beaufort Scale, a wind speed of $5 \mathrm{~m} / \mathrm{s}(18 \mathrm{~km} / \mathrm{h})$ is defined as gentle (leaves and small twigs move) and $10 \mathrm{~m} / \mathrm{s}$ $(36 \mathrm{~km} / \mathrm{h})$ as fresh (small trees in leaf begin to sway). Although not measured, the wind speed during Trials 1-4 (fine weather) was unlikely to have exceeded this range and therefore the spread range determined in our trials is similar to that reported by Ernst et al. (1992) taking the lower height of our plants into account. Cheplick (1998) also reported similar dispersal distances for other grasses lacking dispersal appendages. The perpendicular distances measured in both the mowing and natural trials showed $66-80 \%$ of the seeds fell within $20-25 \mathrm{~cm}$, well within the wind-assisted dispersal of even a light wind $(0.82$ $\mathrm{m}$ at $2.5 \mathrm{~m} / \mathrm{s}$ ). These wind velocities at the road edge may easily be achieved by the passing of large trucks (Ruck \& Lichtneger 2014).

Seed viability was evaluated only in the cut grass mulch. In Trials 6 and 7, the seeds collected on the sticky traps were $>95 \%$ individual seeds that had fallen free of the seed head. As these seeds had separated from the seed-head they were likely to be viable and this was confirmed by their germination in the cut grass mulch. In Trial 5 however, $>95 \%$ of the seeds collected on the sticky traps remained attached to the seed heads, indicating that they may not have been fully mature. This result is supported by the fact that no seedlings emerged from the cut grass mulch. Thus, it is possible that the high seed numbers from Trial 5 would not result in effective dispersal and plant establishment. If this is the case, then dispersal distances of mature seeds by the mowing process may be overestimated.

Of greater concern for long-distance dispersal are the seeds that were embedded in the cut grass mulch and those free on top of the mower. These could be separated from the mower at great distances from where they were collected (Von Der Lippe \& Kowarik 2007). There were relatively few yellow bristle grass seeds found in the cut grass mulch but they could be dislodged whenever the mower was bumped or when the mulch became too heavy and fell off. The free seeds on top of the mower could shake off at any time or may be blown off when the mower was transported on the back of a truck. These events could occur many kilometres from where the seeds were attached leading to rapid and longdistance dispersal of this weed.

\section{CONCLUSIONS}

The mowing of mature yellow bristle grass plants may not disperse their seeds much further than

Table 1 Number of yellow bristle grass seeds found in the cut grass mulch under the mower and the 'free' seeds on the top of the mower for Trials 5-7.

\begin{tabular}{llcc}
\hline Trial no. & Trial date & $\begin{array}{c}\text { Seeds in cut mulch } \\
\text { Number/kg mulch }\end{array}$ & $\begin{array}{c}\text { Seeds 'free' on top of mower } \\
\text { Number }\end{array}$ \\
\hline 5 & 27 February 2014 & 0 & 89 \\
6 & 27 February 2014 & 6 & 154 \\
7 & 6 March 2014 & 19 & 267 \\
\hline
\end{tabular}


it could naturally be spread on a windy day. However, during mowing seeds accumulate in the cut grass mulch under the mower and on top of the implement. These seeds could drop off at much larger distances. This shows that mowers could spread the weed for many kilometres - as far as the mower is driven or transported without being cleaned.

\section{ACKNOWLEDGEMENTS}

Thanks to Katherine Tozer and Mark Shaw for help with Trials 1-4, Trevor Power and Mike Parker for the mowing (Trials 5-7) and Chris Buddenhagen for manuscript comments and generation of Figure 2. This project was funded by the Ministry for Primary Industries, DairyNZ, Foundation for Arable Research, Waikato Regional Council, Environment BoP and Horizons Regional Council.

\section{REFERENCES}

Bailleul D, Ollier S, Huet S, Gardarin A, Lecomte J 2012. Seed spillage from grain trailers on road verges during oilseed rape harvest: an experimental survey. PloS One 7, e32752.

Birdsall JL, McCaughey W, Runyon JB 2012. Roads impact the distribution of noxious weeds more than restoration treatments in a lodgepole pine forest in Montana, USA. Restoration Ecology 20: 517-523.

Bryson CT, Carter R 2004. Biology of pathways for invasive weeds. Weed Technology 18: 1216-1220.

Champion P, James TK, Popay AI, Ford K 2012. An illustrated guide to common grasses, sedges and rushes of New Zealand. New Zealand Plant Protection Society, Lincoln, New Zealand 208 pp.

Cheplick GP 1998. Seed dispersal and seedling establishment in grass populations. Population biology of grasses. Cambridge University Press, Cambridge, United Kingdom pp. 84-105.

Christen D, Matlack G 2006. The role of roadsides in plant invasions: a demographic approach. Conservation Biology 20: 385-391.

Clifford HT 1959. Seed dispersal by motor vehicles. Journal of Ecology 47: 311-315.

Ernst WH, Veenendaal EM, Kebakile MM 1992. Possibilities for dispersal in annual and perennial grasses in a savanna in Botswana. Vegetatio 102: 1-11.

Hintze C, Heydel F, Hoppe C, Cunze S, König A, Tackenberg O 2013. D3: the dispersal and diaspore database-baseline data and statistics on seed dispersal. Perspectives in Plant Ecology, Evolution and Systematics 15:180-192.

Hogan JP, Phillips CJC 2011. Transmission of weed seed by livestock: a review. Animal Production Science 51: 391-398.

James TK, Tozer KN, Rahman A 2009. Yellow bristle grass; a recent weed incursion in Waikato dairy pastures. Proceedings of the New Zealand Grassland Association 71: 3942.

James TK, Dowsett CA, Trolove MR 2015. Identification and enumeration of weed seeds in chopped maize being transported for silage. New Zealand Plant Protection 68:118123.

Kalwij JM, Milton SJ, McGeoch MA 2008. Road verges as invasion corridors? A spatial hierarchical test in an arid ecosystem. Landscape Ecology 23: 439-451.

Ruck B, Lichtneger P 2014. Wind loads on flat boards and walls induced by passing vehicles. 11 p. https://www.gala-ev.org/images/ Beitraege/Beitraege\%202014/pdf/14.pdf (accessed 16 May 2019).

Tozer KN, Cameron CA, James TK 2012. Changes in yellow bristle grass (Setaria pumila) incidence in Waikato dairy pastures over 4 years. New Zealand Plant Protection 65:54-58.

Tozer KN, James TK, Brier B 2014. Modelling the economic impact of yellow bristle grass (Setaria pumila) on a Waikato dairy farm. In Proceedings of 5th Australian Dairy Science Summit: 255-258.

Von Der Lippe M, Kowarik I 2007. Long-distance dispersal of plants by vehicles as a driver of plant invasions. Conservation Biology 21: 986-996. 